\title{
Transfacial Surgical Approaches to Secure Wide Exposure of the Skull Base
}

\author{
Sin Rak Kim ${ }^{1}$, \\ Jung Woo Lee ${ }^{1}$, \\ Yea Sik Han ${ }^{1}$, \\ Han Kyu Kim² \\ ${ }^{1}$ Department of Plastic and \\ Reconstructive Surgery, Kosin University \\ College of Medicine, Busan; \\ ${ }^{2}$ Department of Neurosurgery, \\ Bundang Jesaeng General Hospital, \\ Seongnam, Korea
}

No potential conflict of interest relevant to this article was reported.

\begin{abstract}
Background: Treatment of skull base tumors is challenging due to limited access and presence of important neurovascular structures nearby. The success of a complete tumor resection depends on the extent of tumor exposure and secure field of view. While these tumors are often removed by transcranial endoscopic access, transfacial approach is sometimes required depending on the location and size of the tumor. This study describes various transfacial approaches in patients undergoing skull base tumor resection. Methods: From March to November 2013, 15 patients underwent skull base tumor resection via transfacial accesses at a tertiary institution. Data were reviewed for patient demographics, type of access used, completeness of tumor resection, surgical outcome, and postoperative complications.

Results: Two clivus tumor patients underwent transmaxillary approach; three tuberculum-sellae and suprasellar-hypothalamus tumor patients underwent transbasal approach; three clinoid and retrobulbar intraconal orbital tumor patients underwent orbitozygomatic approach; and seven petroclival-area, pons, cavernous sinus, and lateral-sphenoid-wing tumor patients underwent zygomatic approach. In all cases, the upper and lower margins of the tumor were visible. Complete tumor removal consisted of 10 cases, and partial tumor removal in 5. There were no immediate major complications observed for the transfacial portion of the operations. The overall cosmetic results were satisfactory. Conclusion: Plastic surgeons can use various transfacial approaches according to the location and size of skull base tumors to secure a sufficient field of view for neurosurgeons.
\end{abstract}

Keywords: Skull base / Neoplasms

\section{INTRODUCTION}

The skull base has a complex anatomy and contains important neurovascular structures. It can be divided into three zones based on anatomical features. Zone I begins at the anterior midline and extends to the posterior wall of the orbit toward the greater occipital foramen. Tumors in Zone I originate from the paranasal sinus and mid-facial skin and invade into the cribriform plate and dura mater towards the brain. Zone II includes the infratemporal fossa, the pterygopalatine fossa, and part of the middle cranial fossa lo-

\section{Correspondence: Yea Sik Han}

Department of Plastic Surgery, Kosin University College of Medicine,

262 Gamcheon-ro, Seo-gu, Busan 602-702, Korea

E-mail: hanplastic1@naver.com

Received December 8, 2014 / Revised February 23, 2015 / Accepted April 2, 2015 cated above the pterygopalatine fossa. Zone-II tumors consist of clival chordoma and meningioma. They are less prevalent but have poorer prognoses compared to Zone-I tumors. Zone III includes the posterior fossa and the posterior part of the mid-cranial fossa. Glomus jugulare tumor, neurinoma, and squamous cell carcinoma may manifest in this zone (Fig. 1) [1]. Surgical access to the skull base is limited due to the centrality of lesions surrounded by neurovascular structures. In many cases, typical transcranial approaches are insufficient for adequate visualization and resection of skull base tumors [2]. Recently, various minimally invasive approaches, including the endoscopic endonasal approach, have come to be widely used. Yet, other approaches are still required for complete tumor removal [3].

The transfacial access is provided by a plastic surgeon and can 
provide the neurosurgeon with sufficient operative vision for removing skull base tumors. Appropriate surgical access decreases the risk of traction damage to brain and cranial nerves as well as complications such as facial deformities and functional problems [2]. In this study, we review 15 successful cases of skull base tumor resection using combined transcranial and transfacial approaches.

\section{METHODS}

Of the skull base tumor patients visiting our hospital from March to November 2013, 15 patients had lesions inaccessible through typical transcranial approaches and were selected for review. Depending on tumor characteristics, the skull base was accessed through of LeFort I transmaxillary, transbasal, zygomatic, or orbitozygomatic approaches. Medical charts were reviewed for patient demographics, type of access used, completeness of tumor resection, surgical outcome, and postoperative complications.

\section{RESULTS}

The subjects consisted of six male and nine female patients. The mean age was 41.2 years (range 17 to 75 years). Tumor histology was consistent with meningioma $(n=9)$, chordoma (2), pilocytic

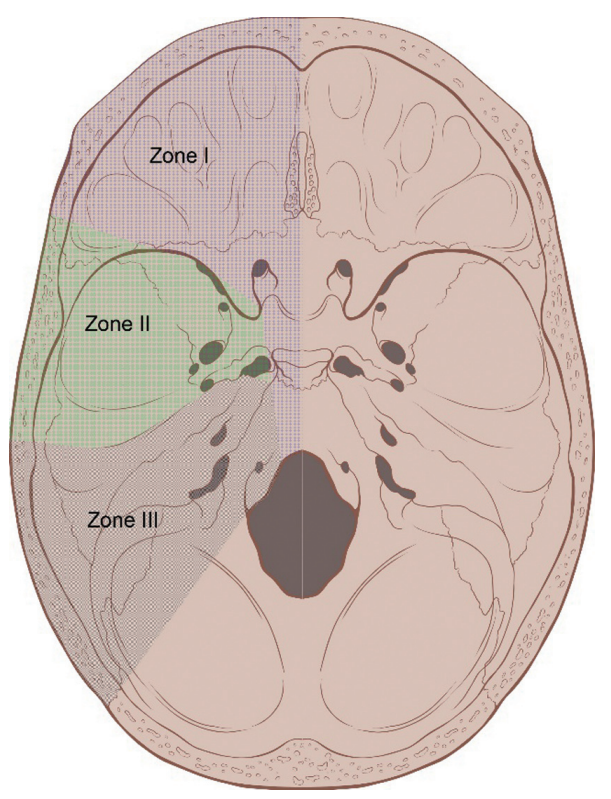

Fig. 1. The three zones of the skull base. astrocytoma (1), epidermoid cyst (1), cavernous malformation (1), and hemangioma (1).

A brain MRI was conducted in all cases, and cerebral angiograms were also obtained as necessary. The imaging studies identified two clival tumors, three petroclival tumors, two clinoid tumors, one pons tumor, one lateral sphenoid wing tumor, one suprasellar hypothalamus tumor, two tuberculum sellae tumors, one cavernous sinus tumor, one sphenoorbital tumor, and one retrobulbar intraconal orbital tumor. The mean radiographic tumor diameter was $3.6 \mathrm{~cm}$. Six tumors had a diameter less than 3 $\mathrm{cm}$; five cases were between $3 \mathrm{~cm}$ and $5 \mathrm{~cm}$; and four cases were greater than $5 \mathrm{~cm}$ or more.

The transfacial route was determined in consultation with neurosurgeons and depended on tumor location, size, growth direction, relationship to surrounding structures, and expected pathologic findings. Tumor location and size were major determinants. Clival tumors were accessed via transmaxillary approach with LeFort I osteotomy and midline split osteotomy (Fig. 2). Su-

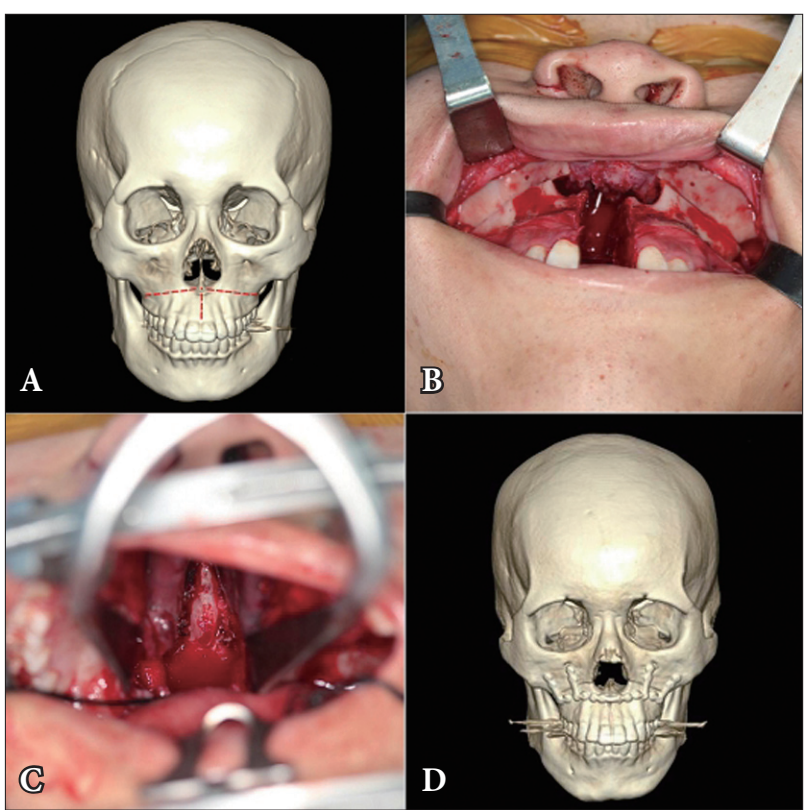

Fig. 2. A 17-year-old male patient with clival chordoma who underwent LeFort I transmaxillary approach. (A) The red dotted line shows the site of the osteotomy in the maxilla: from the pyriform aperture to the bilateral pterygomaxillary junction. (B) Operative photograph of the osteotomy in the maxilla, and the sagittal osteotomy in the midpalate. (C) For easy access to the clivus, each half of the maxilla was laterally pushed aside. (D) Postoperative 3-dimensional facial computed tomography shows that the facial skeleton was reassembled. 
prasellar hypothalamus and tuberculum sellae tumors were accessed via transbasal approach with orbitofrontal osteotomy (Fig. 3). Petroclival, pons, sphenoid wing, cavernous sinus, and sphenoorbital tumors were accessed through the zygoma (Fig. 4). Clinoid and retrobulbar intraconal orbital tumors were approached through orbitozygomatic osteotomy (Fig. 5). All of the bone fragments generated from the osteotomy were preserved. Plate registration was conducted for accurate restoration of the bone fragments to the respective positions (Fig. 6).

Each tumor resection was classified as either complete or partial. A tumor resection was considered complete if the whole of tumor could be removed at the time of operation. If a portion of the tumor was left behind, the resection was considered partial. Of the whole, 10 resections (67\%) were complete with the remaining 5 resections (33\%) being partial (Table 1). Complete resection was achieved in one transmaxillary approach (1/2), one transbasal approach (1/3), six zygomatic approach cases (6/7), and two orbitozygomatic approach $(2 / 3)$

None of the patients required major complications requiring

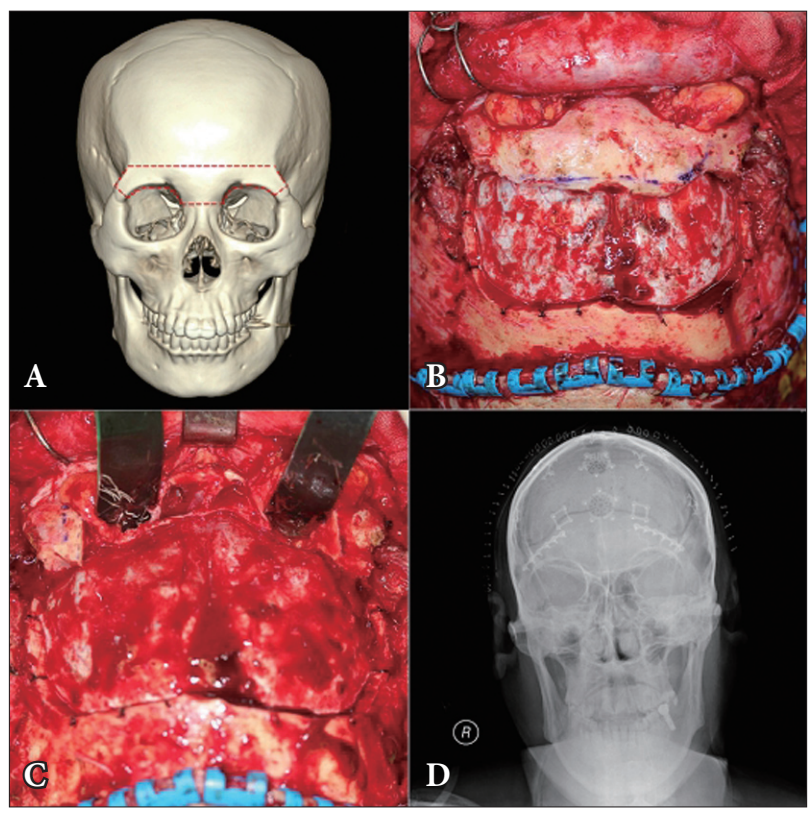

Fig. 3. A 60-year-old male patient with tuberculum sellae meningioma who underwent transbasal approach. (A) The red dotted line shows the site of the osteotomy that includes the entire superior orbital rim and nasion. (B) The frontal bone flap was removed and the osteotomized orbital bar was revealed. (C) After the orbital bar was removed, intraorbital exposure was performed. (D) The postoperative anterior-posterior skull X-ray shows the repaired orbital bar.

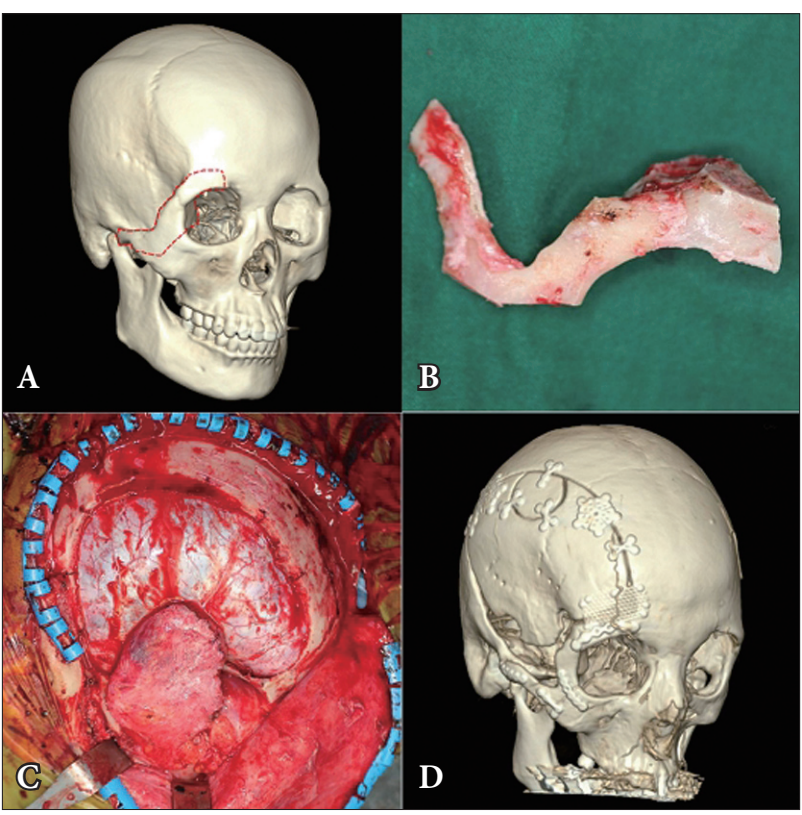

Fig. 4. A 31-year-old female patient with clinoid meningioma who underwent orbitozygomatic approach. (A) The red dotted line shows the site of the osteotomy in the orbital roof and zygomatic arch. (B) Through osteotomy, the bone segment was separated. (C) For the wide exposure of the clinoid, the orbitozygomatic bone segment was removed. (D) Through postoperative 3-dimensional facial computed tomography, the orbitozygomatic bone flap was fixed using titanium plates.

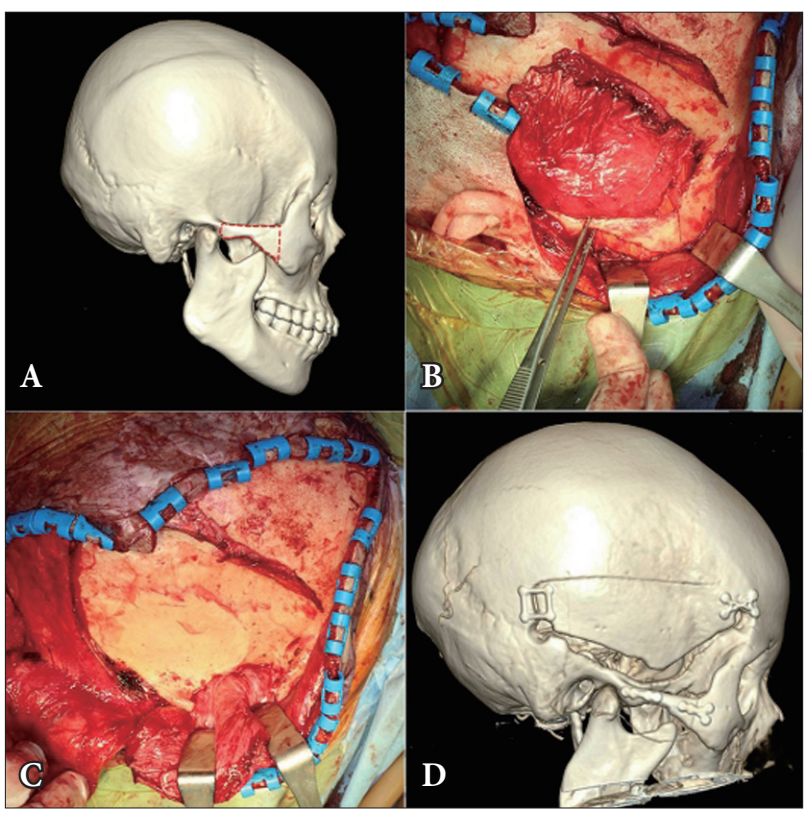

Fig. 5. A 45-year-old female patient with lateral sphenoid wing meningioma who underwent zygomatic approach. (A) The red dotted line shows the osteotomy site at the zygomatic arch. (B) Osteotomy was performed at the zygomatic arch. (C) After the zygomatic arch was removed, the temporalis muscle was pushed down to expose the petroclival area. (D) The postoperative 3-dimensional facial computed tomography image shows the repaired zygomatic arch. 
surgical revision in the immediate postoperative period for the transfacial passages. One of the patients who had undergone transmaxillary approach reported tingling sensation in both cheeks, but this resolved without specific treatment. One patient who had transbasal approach was found to have subcutaneous

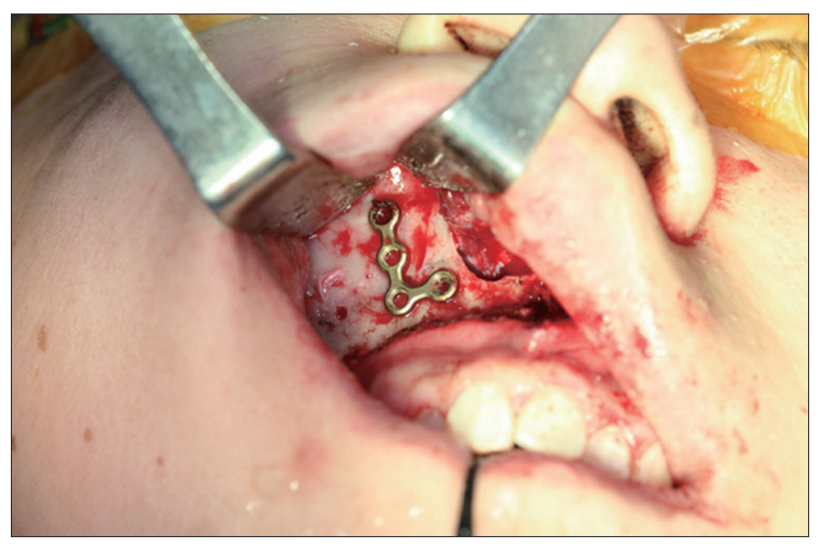

Fig. 6. Plate registration. To restore bone fragments to their exact original locations, the osteotomy line was marked with a marking pen. A microplate used for fixation was placed over the line, drilled, and then registered. emphysema of the forehead, but this symptom also subsided without intervention. One patient suffered from bilateral ptosis, which was later corrected with a tensor fascia lata sling. The mean follow-up period was twelve months (range seven to sixteen months). All patients were satisfied with cosmetic outcomes. The patients remained symptom free during the follow-up period.

\section{DISCUSSION}

Treatment of skull base tumors is challenging due to limited access and presence of important neurovascular structures nearby. However, a growing understanding of the surgical anatomy and development in surgical methods have improved the access to the skull base. Moreover, cooperation among clinicians from neurosurgery, plastic surgery, otorhinolaryngology, and radiology has produced favorable results [2].

With developments in stereotactic radiosurgery and endoscopic technology, various minimally invasive approaches are being em-

Table 1. Overview of 15 consecutive patients treated via transfacial approach

\begin{tabular}{|c|c|c|c|c|c|c|c|c|}
\hline Case & Sex/Age & Diagnosis & Location & $\begin{array}{l}\text { Tumor size } \\
\left(\mathrm{cm}^{2}\right)\end{array}$ & $\begin{array}{l}\text { Approach } \\
\text { method }\end{array}$ & $\begin{array}{l}\text { Tumor } \\
\text { removal }\end{array}$ & Complications & $\begin{array}{l}\text { Combined } \\
\text { flap }\end{array}$ \\
\hline 1 & Male/24 & Granuloma & Clivus & $4.5 \times 3.5$ & $\begin{array}{l}\text { LeFort I transmaxillary } \\
\text { approach }\end{array}$ & Partial & None & None \\
\hline 2 & Female/46 & Chordoidglioma & Suprasellar hypothalamus & $3.1 \times 2.7$ & Transbasal approach & Partial & $\begin{array}{r}\text { Subcutaneous } \\
\text { emphysema }\end{array}$ & $\begin{array}{l}\text { Pericranial } \\
\text { flap }\end{array}$ \\
\hline 3 & Female/56 & Meningioma & Right petroclival area & $3.7 \times 3.1$ & Zygomatic approach & Total & None & None \\
\hline 4 & Female/54 & $\begin{array}{l}\text { Cavernous } \\
\text { malformation }\end{array}$ & Pons & $2.3 \times 1.9$ & Zygomatic approach & Total & None & None \\
\hline 5 & Female/53 & Meningioma & Left petroclival area & $5.2 \times 3.8$ & Zygomatic approach & Total & None & None \\
\hline 6 & Female/31 & Meningioma & Right clinoid & $5.7 \times 5.3$ & Orbitozygomatic approach & Total & None & None \\
\hline 7 & Female/45 & Meningioma & Right lateral sphenoid wing & $4.9 \times 4.5$ & Zygomatic approach & Total & None & None \\
\hline 8 & Male/53 & Meningioma & Tuberculum sellae & $2.8 \times 2.6$ & Transbasal approach & Partial & None & $\begin{array}{l}\text { Pericranial } \\
\text { flap }\end{array}$ \\
\hline 9 & Female/67 & Epidermoid cyst & Left cavernous sinus & $0.8 \times 1.7$ & Zygomatic approach & Total & None & None \\
\hline 10 & Male/17 & Chordoma & Clivus & $1.0 \times 1.1$ & $\begin{array}{l}\text { LeFort I transmaxillary } \\
\text { approach }\end{array}$ & Total & $\begin{array}{l}\text { Temporary tingling } \\
\text { sensation in the } \\
\text { cheek }\end{array}$ & None \\
\hline 11 & Female/75 & Meningioma & Right clinoid & $6.3 \times 5.4$ & Orbitozygomatic approach & Total & None & None \\
\hline 12 & Female/30 & Meningioma & Left spheno-orbital area & $3.4 \times 2.2$ & Zygomatic approach & Partial & None & None \\
\hline 13 & Male/60 & Meningioma & Tuberculum sellae & $2.1 \times 1.5$ & Transbasal approach & Total & $\begin{array}{l}\text { Post-surgical } \\
\text { ptosis }\end{array}$ & $\begin{array}{l}\text { Pericranial } \\
\text { flap }\end{array}$ \\
\hline 14 & Male/17 & Hemangioma & $\begin{array}{l}\text { Right retrobulbar intraconal } \\
\text { area }\end{array}$ & $2.9 \times 1.6$ & Orbitozygomatic approach & Partial & None & None \\
\hline 15 & Male/72 & Meningioma & Petroclival area & $5.0 \times 4.1$ & Zygomatic approach & Total & None & None \\
\hline
\end{tabular}


ployed for skull base tumor operations [3,4]. Gamma knife radiosurgery is used not only for skull base tumors, including metastatic tumors, but also for small or remnant tumors after surgical resection. However, the prognoses are poor for large and recurrent tumors, and the radiation-related complications remain high [4].

The endoscopic approach requires that a tumor be removed in fragments and, for this reason, cannot be used for extremely large tumors or tumors in difficult-to-reach locations. The approach is more appropriate for small tumors with clear stalks. When severe bleeding develops and adequate hemostasis is not possible, the endoscopic operation cannot be continued. The endoscope requires an extra hand in the operating room and has a higher learning curve [1].

Transfacial accesses to the skull base require adequate knowledge and practice in creating various safe passages through the soft tissues and facial bone. The transfacial approach is used to fully expose the skull base lesions and to provide surgeons with a direct and wide operative view of deep lesions, which are very difficult to access through endoscopic or transcranial methods [2]. Through the transfacial approach, intraoperative brain traction can be minimized, and damage to neural and vascular structures in the brain can be reduced [5]. The development of various transfacial accesses have sharply decreased operative mortality and morbidity rates, with more acceptable cosmetic outcomes [2]. The transfacial approach includes various techniques such as transfacial swing osteotomy, transnasomaxillary approach, and transpalatal approach [6,7].

The transmaxillary approach, conducted through LeFort I osteotomy, was first suggested by Cheever in 1867. In 1901, LeFort named the current classic fracture line [8], and the osteotomy named after him were used to remove skull base tumors throughout the remainder of last century [9]. Intrasellar tumors and lesions in the upper third layer of the clivus can be accessed using an endoscope. When a clival lesion extends posteriorly beyond the sella turcica, however, the transmaxillary approach is a better solution [10]. Osteotomy is performed using a reciprocating saw. The lateral nasal wall and septum are divided using a guarded osteotome, and the pterygomaxillary fissure is separated using a curved osteotome. The LeFort I fragment is downfractured with finger pressure and mobilized using disimpaction forceps. Optionally, the palate can be split along the midline [11].
An indexing acrylic splint and a posterior transpalatal bar, which are prepared before surgery, must be worn for two to three weeks to maintain accurate occlusion after surgery. A liquid diet is used until appropriate oral hygiene can be maintained. A regular diet is possible from the sixth postoperative week onward [10]. Anticipated complications after surgery include traction injury in the infraorbital nerve, dental root damage, malocclusion, oronasal fistula, velopharyngal dysfunction, and avascular necrosis of the mucosa, bone, and teeth [12]. In our study, one patient with LeFort osteotomy experienced a tingling sensation in both cheeks due to intraoperative traction of the infraorbital nerves. However, this resolved spontaneously, and no other complications were observed.

To access the clivus, transfacial swing osteotomy and the frontopterional approach can be used, but these require a cutaneous incision such as a Weber-Ferguson incision with a resultant scar that is centrally conspicuous [6]. In this study, the clival tumor patients were 17-years-old and 24-years-old, respectively. Thus, the transoral approach was used to avoid the incisional scar. The patients were satisfied with the cosmetic results.

The transbasal approach is used to access midline cranial base tumors [13]. Three methods are used according to tumor location. The transfrontal approach involves osteotomy of the frontal bone, supraorbital bar, and nasion, and this method is mainly used to secure operative access to the anterior cranial fossa. In the transfrontonasal approach, the medial canthal tendon is detached during orbital bar osteotomy. The nasal bone, the medial orbital wall and the roof is also fractured. This second variant is used to access the anterior cranial fossa and nasopharynx for an anteriorly growing clival tumor. The transfrontonaso-orbital approach is similar to the transfrontonasal approach, but with an additional osteotomy of the lateral orbital wall and the orbital roof. This third variant is mainly used to access large anterior cranial fossa tumors, nasopharyngeal lesions, and anteriorly growing clival tumors [6,14]. In our study, the tumors were located at the tuberculum sellae and suprasellar hypothalamus and were all less than 3 $\mathrm{cm}$. Thus, the transfrontal approach was used.

The authors performed an osteotomy along with a line connecting points that are located $1 \mathrm{~cm}$ inferior to superior temporal line, more lateral to lateral orbital rim, and $6 \mathrm{~cm}$ superior to nasion 
and nasion by using a reciprocating saw.

The transbasal approach has the potential for an ascending infection via the nasofrontal duct. To prevent infection, the nasofrontal duct entrance must be closed using a pericranial flap [15]. In our study, the pericranial flap was interposed between the orbitofrontal bone segment and the frontal sinus. In one case utilizing the transbasal approach, subcutaneous emphysema developed in the forehead. This was considered to originate from failure to seal the nasofrontal duct entrance, and prophylactic antibiotics were administered. The patient did not develop any signs of infection, and the subcutaneous emphysema had subsided by day 7 .

In a study by Raso and Gusmao [16], ptosis was a complication in two out of twenty-two skull base tumor patients who underwent the transbasal approach, with one of these two patients requiring surgical correction. In our study, the eldest of three transbasal approach patients, a 60-year-old male, experienced post-surgical ptosis. His symptoms did not improve at one-year follow-up visit and required a tensor fascia lata sling repair. The patient was satisfied with the results. The post-surgical ptosis can be caused by oculomotor nerve injury or by supraorbital fissure syndrome [17]. However, the cause could not be found out in the present case.

The zygomatic approach was first described by Fujitsu and Kuwabara [18] in 1985 and is used to access the pterional area. The full explosure of the lateral temporal dura allows access the middle fossa floor and anterior wall is possible without interference to the temporal muscle. In addition, the lateral wall of cavernous sinus is easy to access [19]. The zygomatic osteotomy includes a $3-\mathrm{cm}$ arch resection for accommodating the temporalis muscle. Other methods include the removal of "a bit" of the zygomatic arch, and the lowering of arch by drilling the upper segment. The former method was used in our series [19]. Through zygomatic arch osteotomy, the fragments can be mobilized downward with the masseteric muscle still attached.

In another method, the masseteric muscle is separated from zygomatic arch prior to osteotomy [20]. The former method has anatomic and time advantages [19]. In this study, the zygomatic arch bone flap was detached from the masseteric muscle in all seven cases. In four cases, the operation was performed in two stages, and the zygomatic arch bone flap was stored in a bone bank for up to ten days before fixation. No patients experienced difficulty with mastication during the follow-up period.

The orbitozygomatic approach was first used to remove a frontotemporo sphenoid meningioma in 1984 [21]. In this method, the anterior and middle cranial fossae, basilar apex region, and upper clivus are fully exposed [22]. The authors performed two-piece orbitozygomatic craniotomy. The frontal dura mater is retracted to sufficiently expose orbital roof, and the temporal muscle is retracted to expose the sphenoid bone and inferior orbital fissure. The frontal skin is pulled down enough to expose the body of zygoma and zygomatic arch. The supraorbital nerves are detached and pulled down together with the skin flap. The periorbital membrane is also carefully detached from the orbital roof. Superior orbital margins are incised, including a large area of the orbital roof. The frontal fundus is detached to expose the superior orbital fissure. The body of zygoma is excised from the inferior orbital fissure, while the periorbital membrane is retracted for protection around the inferior orbital fissure. Thereafter, oblique osteotomy is made on the posterior zygomatic arch. Compared with typical pterional approaches, this method provides a better field of view, a shallower surgical field, and less brain traction [23]. The orbitozygomatic approach is associated with complications such as orbital content damage, optic nerve damage, and poor cosmetic outcomes.

In this study, we tried to minimize postoperative complications through precise placement of bone fragments. To restore bone fragments to their exact original locations, osteotomy lines were marked with a marking pen, and microplates for fixation were placed over the lines, drilled, and then registered before each osteotomy. As a result, the bone segments were re-assembled easily and precisely, and no specific complications were observed.

Despite developments in surgical technique, surgical removal of a skull base tumor is still challenging for surgeons due to difficulty in securing operative vision. This is on account of the complicated anatomical structure of skull base and the presence of cranial nerves and blood vessels. In this study, skull base tumor removal was performed in fifteen cases, using the transmaxillary, transbasal, zygomatic, or orbitozygomatic approaches. Overall complete tumor resection was possible in 10 cases. Therefore, plastic surgeons can use various transfacial approaches according 
to the location and size of skull base tumors to secure a sufficient field of view for neurosurgeons.

\section{REFERENCES}

1. Korean Skull Base Society. Skull base surgery. Seoul: Gunja; 2007.

2. Lee MJ, Kim DH, Cho EJ, Chang SC, Kim HK. The approach of skull base lesions in the view point of plastic surgery. J Korean Soc Plast Reconstr Surg 1997;24:559-69.

3. Snyderman CH, Pant H, Carrau RL, Prevedello D, Gardner P, Kassam $\mathrm{AB}$. What are the limits of endoscopic sinus surgery?: the expanded endonasal approach to the skull base. Keio J Med 2009;58:152-60.

4. Starke RM, Williams BJ, Hiles C, Nguyen JH, Elsharkawy MY, Sheehan JP. Gamma knife surgery for skull base meningiomas. J Neurosurg 2012;116:588-97.

5. Jackson IT. Craniofacial osteotomies to facilitate the resection of tumors of the skull base. In: Wilkins RH, editor. Neurosurgery update I. New York: McGraw-Hill; 1990. p.277-91.

6. Moreira-Gonzalez A, Pieper DR, Cambra JB, Simman R, Jackson IT. Skull base tumors: a comprehensive review of transfacial swing osteotomy approaches. Plast Reconstr Surg 2005;115:711-20.

7. Lawton MT, Beals SP, Joganic EF, Han PP, Spetzler RF. The transfacial approaches to midline skull base lesions: a classification scheme. Oper Tech Neurosurg 1999;2:201-17.

8. Moloney F, Worthington P. The origin of the Le Fort I maxillary osteotomy: Cheever's operation. J Oral Surg 1981;39:731-4.

9. Donald PJ. Transfacial approach. In: Donald PJ, editor. Surgery of the skull base. Philadelphia: Lippincott-Raven; 1998. p. 165-94.

10. Roy S, Patel PK, Tomita T. The LeFort I transmaxillary approach to skull base tumors. Clin Plast Surg 2007;34:575-83.

11. Choung PH. Transfacial approaches to the skull base. J Korean Assoc Oral Maxillofac Surg 1994;20:23-32.

12. Lewark TM, Allen GC, Chowdhury K, Chan KH. Le Fort I osteotomy and skull base tumors: a pediatric experience. Arch Otolaryngol Head Neck Surg 2000;126:1004-8.

13. Derome PJ. The transbasal approach to tumors invading the skull base. In: Schmidek HH, Sweet WH, editors. Operative neurosurgical techniques. New York: Grune\& Stratton; 1988. p.619-33.

14. Feiz-Erfan I, Spetzler RF, Horn EM, Porter RW, Beals SP, Lettieri SC, Joganic EF, Demonte F. Proposed classification for the transbasal approach and its modifications. Skull Base 2008;18:29-47.

15. Kurtsoy A, Menku A, Tucer B, Suat Oktem I, Akdemir H, Kemal Koc R. Transbasal approaches: surgical details, pitfalls and avoidances. Neurosurg Rev 2004;27:267-73.

16. Raso JL, Gusmao S. Transbasal approach to skull base tumors: evaluation and proposal of classification. Surg Neurol 2006;65 Suppl 1:S1:33-1:7.

17. Finsterer J. Ptosis: causes, presentation, and management. Aesthetic Plastic Surgery 2003;27:193-204.

18. Fujitsu K, Kuwabara T. Zygomatic approach for lesions in the interpeduncular cistern. J Neurosurg 1985;62:340-3.

19. Campero A, Campero AA, Socolovsky M, Martins C, Yasuda A, Basso A, Rhoton A. The transzygomatic approach. J Clin Neurosci 2010;17:1428-33.

20. Ustun ME, Buyukmumcu M, Ulku CH, Guney O, Salbacak A. Transzygomatic-subtemporal approach for middle meningeal-to-p2 segment of the posterior cerebral artery bypass: an anatomical and technical study. Skull Base 2006;16:39-44.

21. Pellerin P, Lesoin F, Dhellemmes P, Donazzan M, Jomin M. Usefulness of the orbitofrontomalar approach associated with bone reconstruction for frontotemporosphenoid meningiomas. Neurosurgery 1984;15:715-8.

22. Lee DC, Chang SC. Long term follow up of complications in 43 cases after skull base approach. J Korean Soc Plast Reconstr Surg 1999;26: 1138-45.

23. Lemole GM Jr, Henn JS, Zabramski JM, Spetzler RF. Modifications to the orbitozygomatic approach. Technical note. J Neurosurg 2003;99: 924-30. 